EGU2020-13337

https://doi.org/10.5194/egusphere-egu2020-13337

EGU General Assembly 2020

(c) Author(s) 2020. This work is distributed under

the Creative Commons Attribution 4.0 License.

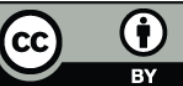

\title{
The difference of sediment sources between high flows and low flows in the Hailuogou Glacier stream
}

\author{
Jiacun Chen ${ }^{1,3}$, Ivan Lizaga ${ }^{2}$, Xinbao Zhang ${ }^{1}$, and Ana Navas ${ }^{2}$ \\ ${ }^{1}$ Chengdu Institute of Mountain Hazards and Environment, Soil and water conservation Department, Chengdu, China \\ (jiacunchen@qq.com) \\ ${ }^{2}$ Estación Experimental de Aula Dei, Spanish National Research Council (EEAD-CSIC), Avda. Montañana1005, Zaragoza \\ 50059, Spain. \\ ${ }^{3}$ University of Chinese Academy of Sciences, Beijing100046, China.
}

In the area of Mt Gongga (Hengduan range, China) most glaciers are experiencing considerable retreat and mass loss since the early 20th century. Drainage of recently deglaciated surfaces delivers fine sediments thus affecting patterns of sediment delivery with impacts on water quality. Research in the area indicates significant differences between sediment at high flows and low flows in the same river during different seasons. High level flows were usually caused by heavy rainfall events or continuous rainfall that erode the slopes by sheet, rill and gully erosion and transport important amounts of sediments to streams leading to significant increases in river sediment flux. During low flows subsurface soil flux during spring and the direct discharge at the outlet of the glacier result in much less sediment load and mean suspended sediment concentration compared with high flows. The runoff volume, hydrograph peak, sediment load and mean suspended sediment concentration in high flows are as much as an order of magnitude higher than in low flows. Therefore, it is of great significance exploring the provenance of fine sediment during high flows and low flows to assess if there are differences in the contributing sources of sediments.

For this purpose during a 2 weeks field campaign in May 2016 in the frame of IAEA INT5153 project, source sediment samples and channel bed sediment mixtures were collected along the river valley of the Hailuogou Glacier. Three main sources were identified: surface glacier materials, old moraines and recent moraines. Composite surface samples $(2 \mathrm{~cm})$ were created of 10 subsamples in each representative site for surface glacier materials. Following the same scheme on old lateral moraines 10 sites were selected from the more mineral blocky deposits to the most vegetated parts at higher altitudes. On recent moraines 12 sites with different stages of vegetation cover were sampled. Starting from the glacier tongue a total of 7 fine sediment mixtures were collected along the river of which 3 composite samples corresponded to the dry season with low flow and 4 samples corresponded to high flow. A new consensus test method and an unmixing model were used to estimate the apportionments of the sediment sources to the sediment loads. The results showed that the contribution of different sources to the sediment mixture deposits varied along the river showing different provenance for the low and high flow suggesting different 
mechanisms of sediment generation during melting and dry seasons. This study is of interest for gaining knowledge on changing dynamics of sediment in regions were the rapid disappearance of glaciers and snow as in Mt. Gongga, has increased the mobilization and transport of sediment loads with consequences for the local population. 